Chronic hydrocephalus is not infrequently met with, but patients with this affection often possess an amount of intelligence above the common among idiots. One case especially I recall in a young woman who died of acute phthisis, in which the brain was a mere shell, containing more than a pint of fluid in the ventricles, which freely communicated with one another. The brain-substance, however, was firm, and weighed about forty-eight ounces. This patient could read well, sing, and was very clever at needlework, though she was hemiplegic and epileptic.

Microcephalics not infrequently possess a fair amount of intelligence.

The digestive functions are, as a rule, weak, diarrhoa being not uncommon, and the breath of many being very offensive. The uterine functions are oftentimes very irregular, and there are frequently outbreaks of temper noticed at the menstrual periods.

Congenital syphilis would not appear to be at all a common condition; a few instances have come under observation, in which psoriasis and condylomata of the anus have seemed to indicate it. But the absence of evidence of syphilis having existed in the parents, and the infrequency of interstitial keratitis, involve the subject in some obscurity.

Deformities of various kinds often exist, principally as club-foot, curvature of the spine, malformations of the palate and ear, and, more rarely, non-symmetrical cranium. The malformation of the palate exists in a very large proportion of idiots and imbeciles, and consists in its being narrow and highly arched. Apparently it is connected with a deficiency in the development of the anterior lobes of the cerebrum.

Idiots are subject to other diseases than those specially dwelt upon in much the same proportion as in other classes of the community, though the mortality is probably somewhat greater from the feeble vitality.

Nenthead, Alston, Cumberland.

\section{WRACTURE OF THE EPIPHYSIS OF THE TROCHANTER MAJOR, AND ITS CONSEQUENCES.}

BY JOHN HENRY ASHTON, MEDICAL OFPICER OF THE FREEBRIDGE LYNN UMION.

AUGUSTUS $R \longrightarrow$, a well-developed boy of sixteen years of age, was brought to me on August 27th, suffering from great pain in the hip and parts around. He informed me, in answer to my inquiry, that he had not been hurt or injured in any way. This, I some days after learned, was untrue, as he had been swung by his companions in the harvest field-i.e., two men took hold of each of his legs and arms and swung him, and afterwards bumped him on the ground. I found the whole thigh and parts around the hip greatly swollen and tender. Any movement of the joint caused intense pain. No bruises were visible. The measurements of both sides, from the anterior superior spine of the ilium to the trochanter major, and from the same process to the patella, were the same on both sides. No crepitus was felt; the tongue was black; the pulse rapid, weak, and irregular; constant delirium was present. I ordered leeches to be applied, and bark and tincture of opium to be given, and the limb to be placed on pillows in the position most comfortable. After a fortnight his constitutional state improved, but the limb had lengthened to the extent of an inch or more, and fluctuation was apparent. I ordered his removal to the West Norfolk and Lynn Hospital. He was admitted there on Sept. 16th, under the care of Dr. Lowe. I was informed by the house-surgeon that an abscess was opened, and that afterwards crepitus could be felt by grasping the trochanter and moving the limb. The boy died a fortnight after his admission.

By the kindness of Mr. Priestley I was shown the condition of the parts after the post-mortem examination. The trochanter was fractured, and broken completely from the shaft. The joint was destroyed, and the neck and upper part of the femur were in a state of necrosis.

This boy, after being bumped, continued his work until Saturday evening. He told me that he then for the first time felt some stiffness. On the following Monday and Tuesday he went as usual to his work, walking two or three miles night and morning. The joint had then become very painful and stiff, and he remained at home until I saw him. Such cases are extremely rare; and the only positive means of diagnosis would be crepitus on moving the limb, and immovability of the fracment. I was unable to arrive at a diagnosis of this case owing to the inflammation of the parts around limiting motion. Dr. Lowe did so after his admission to the hospital. It would be well to bear in mind that with this fracture no osseous union might take place, and that a patient might continue his occupation until irritation of the neighbouring parts is set up, as the shaft of the bone continues uninjured.

Gayton, King's Lynn.

\section{g) dithrot}

\section{H O S P TA I P R A T I E, BRITISH AND FOREIGN.}

Nulla antem est alia pro certo noscendi via, nisi quamp] urimas et morborum et dissectionum historias, tum aliorum, tum proprias collectas habere, th inter se comparare.-MoRgAGN De Sed. et Caus. Morb., lib. iv. Procemium.

\section{ST. GEORGE'S HOSPITAL.}

For the notes of the following cases we are indebted to Mr. Bennett, house-surgeon.

FRACTURE OF OUTER CONDYLE OF FEMUR, SIMULATING FRACTURED PATELLA.

(Under the care of Mr. Prescott Hewett.)

J. C_-, a stonemason, aged sixty-eight, whilst clinging to a rope in order to put some pulleys right, lost his hold, and fell about twelve feet; his right knee, which was bent, coming violently in contact with the ground. On attempting to rise he was unable to do so, and was therefore at once carried to the hospital.

On admission, on Nov. 8th, the patient complained of great pain in the right knee and inability to move the joint. The leg on the affected side was semiflexed, and there was some effusion into the knee-joint, on the outer side of which there was a bruise. When the hand was placed on the front of the joint, two movable pieces of bone could be felt, lying one above the other, with a depression between them in which a finger could be placed. Of these two pieces the lower was considerably larger than the upper. These signs at first sight seemed to indicate a transverse fracture of the patella through its upper part, but on closer examination this bone appeared to be entire. The upper portion of bone was a little to the outside of the lower, and on rubbing the pieces together no crepitus could be felt. On feeling for the lower border of the external condyle of the femur, and tracing it forwards, it seemed to terminate abruptly; and now, when the loose bone lying above the patella was pressed backwards and rubbed against the external condyle, crepitus was very easily obtained.

The patient was sent to bed, and a ham splint put at the back of the limb, which was swang in a Salter's swing After this he did well; and as the effusion in the synovial membrane disappeared, which it did at the end of a week, the portion of bone which had been chipped off gradually fell back, came into contact with the broken surface of the femur, and in a month was firmly united in its original situation.

FRACTURE OF UPPER JAW; EMPHYSEMA OF FACE AND NECK.

M. J-, a plasterer, aged twenty-three, was admitted November 18th. The patient was subject to epileptic attacks, and, during a fit, fell from the platform of a railway station on to the line, striking the left cheek violently against one of the rails. On applying for admission he had recovered from the effects of the fit, and complained of soreness over his left cheek, and pain when he attempted to open or shut his mouth, the pain being much increased when he tried to chew anything, or when he pressed the teeth together. The left side of the face was swollen and diseoloured. On examining the swelling, slight but distinct 
emphysema could be detected as far down as the lower border of the under jaw, extending backwards to the ramus. On passing the finger along the left superior maxilla above its alveolar border, the lower part of the malar process was found to be much flattened, compared with that of the opposite side, and running backwards from that point was a sharp ridge which seemed to extend to the posterior border of the bone. The tissues over this elevation were emphysematous, there was great pain on pressure, and the teeth below were very tender when touched, but no bony crepitus could be felt.

The patient was ordered to be kept quiet, and put on a fluid diet.

On November 19th the emphysema had extended down. wards as far as the hyoid bone, and backwards behind the ramus of lower jaw.

On the 20 th, emphysema had reached the level of cricoid cartilage. The pain on moving the jaw was still very great, and the swelling of cheek had increased a little.

On the 21st, emphysema began to disappear and the swelling to subside.

On the 23rd the emphysema had entirely gone, and the pain on moving the jaw and on pressing on the teeth was less. From this time patient gradually progressed, and on December 9th, when he was discharged, the mouth could be opened and shut, and he could chew meat with very slight discomfort indeed. The lower part of malar process remained depressed, and the elevation running backwards still remained much as it was on admission.

\section{SEAMEN'S HOSPITAL, GREENWICH.}

\section{COMPOUND DEPRESSED FRACTURE OF CRANIUM;} PYAEMIA ; DEATH.

(Under the care of Mr. W. Johnson SMITH.)

IN the "Mirror," vol. i. 1873, page 167, two cases are reported from the above-named hospital of compound depressed fracture of the skull, which recovered without operation. The subjoined case is a further illustration of how much depression and inward projection may exist without the development of bad head symptoms. If this patient had not unfortunately contracted pyæmia there is every probability that he would not have had ang furthex trouble with his head. The case seems to argue for rather than against non-interference in depressed fracture of the skull so long as there are no signs of intra-cranial mischief.

John $\mathrm{R}-$, aged twenty-two, was admitted on Dec. 3rd, 1874, with a deep wound at the back of the head. At 2 P.M. on the previous day he accidentally fell from the deck of his ship to the floor of the engine-room, a distance of about twenty feet. He remained unconscious for half an hour, and then went to his hammock. He was very restless, he states, during the night, suffered much from pain in the head, and vomited frequently. He was able to walk to the hospital, and at the time of his admission did not seem to have been much injured.

On examination of the seat of injury there was found to be a transverse wound of the scalp over the occipital bone near the apex. This was two inches in length, and involved the whole thickness of the soft parts, and at the bottom of the wound, and extending throughout its whole length in the same direction, was a depressed fracture of the cranium; the lower fragment being about one-sixth of an inch below the level of the upper fragment. The edges of the fractured bone were sharp and jagged. The periosteum had not been stripped off, and the soft parts around the seat of injury were not swollen either by effused blood or inflammatory exudation. The patient complained of no bad symptoms save slight headache and weakness of the legs. Pulse 62; temperature $988^{\circ}$.

From the 4th to the 17 th the patient did not present a single bad symptom. He slept well at night, had a good appetite, and felt so well that he of ten complained of being kept in bed. The temperature during this period varied from $98^{\circ}$ to $99^{\circ}$; in the morning it was usually $98^{\circ}$, and in the evening $98 \cdot 6^{\circ}$. The pulse was usually slow, from 62 to 66 ; on and after the 17 th it was never below 70 . The wound had a healthy appearance up to the 17 th, and was then closing by granulation, the fracture being still exposed.
On Dec. 18th the morning temperature was found to be $101 \cdot 3^{\circ}$, and the patient complained of pain at the back of the neck. In the evening he was very feverish, and the axillary temperature was $104^{\circ}$. The patient was perfectly conscious; pupils normal in size and action; no vomiting.

19 th.-Rigors in the morning. Much pain and $\mathrm{swelling}$ (glandular) at back of neck. Soft parts around the wound much swollen. The edges of the wound were separated from the bone below by a director, and exit given to a smali quantity of thin fetid fluid.

From the 20 th to the 25 th the following symptoms were presented: frequent rigors; a temperature usually at or just above $104^{\circ}$, but on one day (the 20th) going down in the morning to $1006^{\circ}$; profuse perspiration; jaundice and pain in the right hypochondriac region; diarrhoea, the stools being fluid and very pale; occasional delirium; dyspnoa and cough; much pain and stiffness at back of neck; difficulty in swallowing, in consequence of sore-throat. The edges of the wound during this period were separated widely from each other, and exposed the fracture and a considerable portion of bone, quite white and deprived of its periosteum. The breathing never became stertorous, nor were any signs of paralysis observed. Death ensued on Dec. 26th, at 3.30 P.Mr.

Post-mortem examination, Dec. 28 th, at 2.30 P.M.-Surface of body of a bright yellow, mottled by large, irregularly. shaped purple patches; the lungs oodematous and much congested; the inferior lobes of both organs studded with numerous small abscesses; liver large and very soft; spleen also enlarged and pulpy; the serous membranes and endocardium stained of a bright yellow colour. About one inch and a half below the apex of the occipital bone is a transverse depressed fracture about two inches in length, the lower edge of which is depressed one-eighth of an inch below the upper edge. About three-quarters of an inch below this fracture is a curved fissure in the bone, the concavity of which is upward; and above the main fracture, at a distance of a quarter of an inch, is another curved fissure. On the inner surface of the occipital bone is an irregular $\mathbf{V}$-shaped fracture, the point of the $\mathbf{V}$ being directed upwards, and projecting into the cranial cavity for a little more than a quarter of an inch. The base of the $\mathbf{V}$ is continuous with the inner table of the bone, and corresponds to the centre of the depressed transverse fracture of the outer table. Corresponding to the apex of the $V$ is a punctured wound of the dura mater and the longitudinal sinus; no traces of intra-cranial effusion of blood at or near the seat of fracture; on inner surface of bone, around the fracture, are a few minute adberent deposits of pale yellow lymph; the dura mater bealthy over the whole of its extent; no purulent deposit above or below this membrane. The longitudinal sinus was not occluded by any large blood-clot, and its lining membrane throughout was pale and healthy in appearance. Brain-tissue softer than usual, but in all other respects quite normal. The lateral ventricles contained a small quantity of reddish and turbid fluid.

\section{ST. BARTHOLOMEW'S HOSPITAL, CHATHAM.}

\section{CASES OF DELAYED UNION OF FRACTURES.}

(Under the care of Mr. A. W. NANEIVELL.)

J. Ks0th, 1870, and sustained compound fracture of both bones of the left leg, two inches above the ankle. He was treated at home till February 15th, 1871, when he was admitted into the hospital. It was then found that the wounds were quite healed, but the bones were not united. A starch bandage was applied at once, and kept on for five weeks. The bones were then found to be firmly united, and the patient was able to walk with the aid of a stick.

T. V-, aged forty, sustained, on March 26th, 1873, a compound comminuted fracture of both bones of the right leg. He was treated in the hospital till June 21st, when he was made an out-patient, a starch bandage having been previously applied. The original wound was unhealed. On October 22nd, 1873, a fresh starch bandage was applied. The tibia was ununited. On May 6th, 1874, the wound being quite healed and the tibia in the same state as at the last report, a plaster-of-Paris bandage was adapted to the limb. This was removed in ten weeks, and the bone was 